\title{
AN EVALUATION OF STUDENT SATISFACTION WITH GIS PROJECT FOR DECISION SUPPORT SYSTEMS AND BUSINESS INTELLIGENCE COURSES
}

\author{
Roger L. Hayen, Central Michigan University, roger.hayen@cmich.edu \\ Zhenyu Huang, Central Michigan University, huang1z@cmich.edu
}

\begin{abstract}
AITP as a worldwide society of information technology business professionals has accommodated a Business Intelligence - Geographical Information Systems (GIS) contest in its annual collegiate conference in the past five years. The contest requires participants to use a commercial GIS application, Excel, and decision making knowledge to solve a 'real-world' business problem. It has been well received by contestants and used by some instructors attending the conference. This study reported the adoption and implementation of the GIS project in its Decision Support Systems/Business Intelligence courses by a large mid-western university. A survey was carried out to find the participants' attitude and perception of the project. Research results show that the GIS project is appropriate for DSS/BI courses and well received by Information Systems undergraduate and graduate students.
\end{abstract}

Keywords: GIS, ESRI, DSS, BI, BAO, Group Project

\section{INTRODUCTION}

Group projects have been well perceived and widely adopted in Information Systems (IS) courses teaching to engage students in active, experiential, and effective learning [1;2]. Research results show that group projects, if managed well, can lead to good learning outcomes such as better deliverables, increased ideas, improved learning experiences, reduced workload, and collective security [7]. However, implementing group projects in IS courses could be a challenge for instructors for a variety of reasons, including the difficulty of selecting or creating appropriate projects relevant to learning purposes, making the project be reflective of 'real-world' situation, dealing with student preferences on individual assignments over group projects due to the consideration of self-sufficiency, social loafing, and schedule challenges [7], as well as managing group projects over a relatively long period of learning process.

Implementing group projects in Decision Support Systems (DSS) and Business Intelligence (BI) courses can improve student learning outcomes in this subject [3]. Similar to group projects used by IS courses; however, the difficulty of selecting, creating, and managing a good DSS \& BI projects also exists. Instructors often have to be creative in the process of implementing group projects in their teaching, for example, adapting real-world cases into classroom projects, or encouraging students to create their own DSS projects to facilitate their learning process and improving learning outcomes [4].

This research reports the adoption of an Association of Information Technology Professionals (AITP) National Collegiate Conference's Business Intelligence competition project into a DSS/BI course taught in a large mid-west university. This BI competition project involves the use of Geographical Information Systems (GIS) tool provided by Environmental Systems Research Institute (ESRI) to solve a common business problem, i.e., site selection for a retail business. The GIS project was used by both graduate and undergraduate courses in fall 2010 semester. Toward the end of the semester, an anonymous survey was conducted to obtain feedback from students about this project. The results show this BI project is well received by students as a good DSS/BI learning tool. Experiences and lessons learned are also reported in this research. 


\section{BACKGROUND}

AITP is a leading worldwide society of information technology business professionals and the community of knowledge for the current and next generation of leaders. One of AITP's premier annual events is the National Collegiate Conference (NCC). The NCC has been held for each of the past 15 years and it continues to attract as many as 800 participants from various colleges and universities in North America.

GIS competition is one of more than a dozen competitions held at NCC. This competition has been included in the NCC for the past five years. GIS BI is one of the competitions with a primary focus on business analytics - the use of information to support business decision making. The primary software used for the BIS competition is Business Analyst Online (BAO) from ESRI. This hosted application features both a very rich set of GIS data and an interface that supports spatial queries of that data. BAO is a GIS tool designed for spatial or geographical queries. Frequently business data is displayed on a map to show spatial relationships. Results from BAO queries are delivered in the Microsoft Excel file format, which readily supports additional analysis in Excel. Excel has been widely recognized as one of the leading software tools for end user BI analysis [5; 6]. More importantly the GIS competition brings in commercially available external information of BAO from ESRI to enhance decision making. The NCC GIS competition problem is therefore adopted as a course group project as students appreciate the ability to use commercially available, leading-edge applications in BI to solve challenging business problems. Some IS instructors have used the NCC GIS competition problem as a case application in their courses and it has been reported well received [3].

\section{GIS PROJECT}

BAO uses maps in analyzing business data. A spatial query is a special type of database query supported by geodatabases. A geodatabase is a database designed to store, query, and manipulate geographic information and spatial data. A geodatabase record can use a geometry data type to represent the location of an object in the physical world and other standard database types to store the object's associated attributes. BAO provides spatial queries in three popular, easy to use arrangements - rings, drive time, and donuts.

Rings, the most widely used for market area analysis, are circles generated on a map around a specified point. It is possible to choose up to three rings and indicate the radius, in miles, of the rings around the point. Report data will be summarized for the area contained within each ring. Drive time represents how long it takes a customer to drive to a specific location. These areas represent the distance traveled from the specified point on the map in a given amount of time. Travel time consideration is taken using posted speed limits per street segments. For instance, a store's ten minute drive-time area defines the area in which drivers can reach the point in ten minutes or less. "Donuts" study areas in a donut shape and provide the traditional ring study area without duplication of overlapping areas. The query data for each area is mutually exclusive. Donuts are useful for understanding the incremental market changes as a customer moves away from a center location. Besides providing these popular spatial query methods, BAO also provides industry non-specific data that is readily understandable to people without an in-depth understanding of a particular business or industry. BAO also contains extensive demographic data such as census data and other econometric data on industry sectors.

The NCC GIS competition problem is revised as a group project and implemented in core IS courses taken by graduate and undergraduate IS majors. The project involves site selection decision making for CJ's Burger, a leader in fresh fast food. CJ's business model is a drive-through style hamburger stand. CJ's Burger was established in 1958 and is a privately owned business. Because of its quality, freshness, and service, CJ's grew steadily to 140 restaurants by 2001. Its Real Estate Development (RED) division is responsible for identifying and opening new stores, including site selection and construction of new stores. The company has decided that Arizona Sales Area is 
a growth region for opening additional stores and six potential locations were identified. A set of key factors and relationships were given to students to evaluate and compare these six locations, which include primary and secondary service areas, households and median income, leakage/surplus factors, cost per store etc. RED uses a project selection method for new stores, which provides a relative score for each of the evaluation parameters. The parameters used in scoring are: cex Index Average, NAICS Leakage, EBT, Payback, and Households (see

Table 1). Students were required to obtain data (spatial, demographic, and economic data) from ESRI BAO about these six locations, and then export the data to Microsoft Excel for further business analytics. Students were required to prepare a three page executive summary based on their data analysis.

\section{METHODOLOGY \& RESULTS}

Students were assigned into groups of three to six to finish the BI GIS project in the fall 2010 semester. Toward the end of the semester, students were asked to finish an anonymous survey regarding the GIS project. The purposes of the survey are to find: 1) students' overall experience with GIS project, 2) if GIS project helps them understand important DSS/BI concepts, 3) if BAO makes external information available and useful for their site selection decision making, 4) their overall satisfaction with the GIS project, and 5) if team size appropriate for the project. The questions of the survey can be found in

Figure 1 highlights the average response for questions 1 through 14 . Overall, these responses indicated that the participants were satisfied with their GIS group project. Several questions (Q3, 7, 9, 15) addressed students' overall experience with the GIS project such as efforts spent on the project, benefits gained from the project, as well as the complexity/easiness of the project. In average, students have positive feedback about the GIS project. They reported that the GIS application (BAO) reduced their efforts in doing additional data analysis in Excel (Q3, mean value of 5.26). In addition, students believed the effort and time they spent on the project was well justified by the benefits they received in better understanding and applying business concepts (Q7, mean value of 4.60). The complexity of the GIS project seems to be just right. The majority thought the project complexity was about just right (Q15, mean value of 2.04 out of 3). However, students might still have experienced some difficulty in performing spatial queries using BAO (Q9, mean value of 4.95). When looking closely at this question, it can be found that $1.8 \%$ strongly disagree, $5.3 \%$ moderately disagree, and $10.5 \%$ slightly disagree that it is easy to perform BAO spatial queries. It reflects that some students may have experience some difficulty in learning the new Geoquery tool.

Table 2. Most questions were assessed with 7-point Likert scale, ranging from 1- extremely dissatisfied/ strongly disagree to 7 - extremely satisfied/ strongly agree, except question 15 and 16 which use 3-point Likert scale to measure project complexity and students' opinions regarding group size for the project. Totally, 57 students turned in complete answers, of which, $19 \%$ were female and $81 \%$ were male, and $58 \%$ were undergraduate while $42 \%$ were graduate students. 
Volume XII, No. 2, pp 250-255, 2011

Table 1. Location Scoring Matrix

\begin{tabular}{|l|l|l|l|l|l|l|}
\hline Location & $\begin{array}{l}\text { cex Index } \\
\text { Avg }\end{array}$ & $\begin{array}{l}\text { NAICS } \\
\text { Leakage }\end{array}$ & EBT & Payback & HH & Score \\
\hline 1 & $\mathrm{xx}$ & $\mathrm{xx}$ & $\mathrm{xx}$ & $-\mathrm{xx}$ & $\mathrm{xx}$ & $\mathrm{xx}$ \\
\hline 2 & $\mathrm{xx}$ & $\mathrm{xx}$ & $\mathrm{xx}$ & $-\mathrm{xx}$ & $\mathrm{xx}$ & $\mathrm{xx}$ \\
\hline 3 & $\mathrm{xx}$ & $\mathrm{xx}$ & $\mathrm{xx}$ & $-\mathrm{xx}$ & $\mathrm{xx}$ & $\mathrm{xx}$ \\
\hline 4 & $\mathrm{xx}$ & $\mathrm{xx}$ & $\mathrm{xx}$ & $-\mathrm{xx}$ & $\mathrm{xx}$ & $\mathrm{xx}$ \\
\hline 5 & $\mathrm{xx}$ & $\mathrm{xx}$ & $\mathrm{xx}$ & $-\mathrm{xx}$ & $\mathrm{xx}$ & $\mathrm{xx}$ \\
\hline 6 & $\mathrm{xx}$ & $\mathrm{xx}$ & $\mathrm{xx}$ & $-\mathrm{xx}$ & $\mathrm{xx}$ & $\mathrm{xx}$ \\
\hline Total & 1.00 & 1.00 & 1.00 & -1.00 & 1.00 & 3.00 \\
\hline
\end{tabular}

Figure 1 highlights the average response for questions 1 through 14. Overall, these responses indicated that the participants were satisfied with their GIS group project. Several questions (Q3, 7, 9, 15) addressed students' overall experience with the GIS project such as efforts spent on the project, benefits gained from the project, as well as the complexity/easiness of the project. In average, students have positive feedback about the GIS project. They reported that the GIS application (BAO) reduced their efforts in doing additional data analysis in Excel (Q3, mean value of 5.26). In addition, students believed the effort and time they spent on the project was well justified by the benefits they received in better understanding and applying business concepts (Q7, mean value of 4.60). The complexity of the GIS project seems to be just right. The majority thought the project complexity was about just right (Q15, mean value of 2.04 out of 3). However, students might still have experienced some difficulty in performing spatial queries using BAO (Q9, mean value of 4.95). When looking closely at this question, it can be found that $1.8 \%$ strongly disagree, $5.3 \%$ moderately disagree, and $10.5 \%$ slightly disagree that it is easy to perform BAO spatial queries. It reflects that some students may have experience some difficulty in learning the new Geoquery tool.

Table 2. GIS Project Assessment Questions

\begin{tabular}{ll}
\hline Item & Questions \\
\hline 1 & $\begin{array}{l}\text { The GIS project helped me understand how business intelligence systems can be used for managerial } \\
\text { problem solving and decision making. }\end{array}$ \\
\hline 2 & $\begin{array}{l}\text { Which of the following best describes your overall level of satisfaction with the GIS project you } \\
\text { completed in this course when learning about business intelligence and integrated business analytics to } \\
\text { support decision making? }\end{array}$ \\
\hline 3 & $\begin{array}{l}\text { The output from the GIS application (BAO) reduced my efforts in doing additional data analysis in } \\
\text { Excel }\end{array}$ \\
\hline 4 & $\begin{array}{l}\text { The GIS project helped me better understand the issues, concepts, and ideas presented in the readings } \\
\text { on business intelligence. }\end{array}$ \\
\hline 5 & $\begin{array}{l}\text { The GIS project helped me better understand the concepts and availability of external information } \\
\text { that can be used to support decision making. }\end{array}$ \\
\hline &
\end{tabular}




\begin{tabular}{ll}
\hline 6 & $\begin{array}{l}\text { The GIS project is the first time I have actually worked with commercially available external } \\
\text { information in conducting a business analysis. }\end{array}$ \\
\hline 7 & $\begin{array}{l}\text { The effort and time spent on the GIS project was greater than the benefit received in better } \\
\text { understanding and applying business concepts }\end{array}$ \\
\hline 8 & $\begin{array}{l}\text { The GIS project helped me to better understand the concepts, ideas, and importance of spatial queries } \\
\text { in the analysis of business information. }\end{array}$ \\
\hline 9 & It was easy for me to perform spatial queries using the GIS application (BAO) \\
\hline 11 & $\begin{array}{l}\text { The GIS project increased my desire to learn more about business intelligence using geographical } \\
\text { information? }\end{array}$ \\
\hline 12 & Overall, the teamwork required by the GIS project helped me improve my communication and \\
\hline 13 & $\begin{array}{l}\text { Completing the GIS project assignment individually would have been better than working on it as a } \\
\text { team. }\end{array}$ \\
\hline 14 & Which of the following best describes your overall level of satisfaction with the GIS project used in this \\
& Course
\end{tabular}

One of the most important reasons of adopting the GIS project in DSS/BI courses is to use the hands-on project to help students understand sophisticated decision making and modeling concepts, processes, and issues. Several survey questions $(\mathrm{Q} 1,4,8)$ were used to assess the functions of the GIS project in this aspect. The average mean values of these three questions are well above 5. Students reported that the GIS project helped them understand how business intelligence systems can be used for managerial problem solving and decision making (Q1, mean value of 5.60). Up to $87.7 \%$ students agreed that the project was helpful in their understanding of decision making process. In addition, 79\% students agreed that the GIS project helped them better understand the issues, concepts, and ideas presented in the readings on BI (Q4, mean value of 5.35). Students found that the project helped them understand abstract DSS/BI theories and concepts. By working on the project, they could really tie the decision making processes, i.e., data extraction from ESRI BAO, model building, and data analysis in MS Excel, with the final results, i.e., the new burger store site selection decision, together. Not only so, students learned from the project the use of new tool and skill: spatial query. Up to $77.2 \%$ students agreed that the GIS project helped them better understand the concepts, ideas, and importance of spatial queries in the analysis of business information (Q8, mean value of 5.18). 


\section{Issues in Information Systems}

Volume XII, No. 2, pp 250-255, 2011

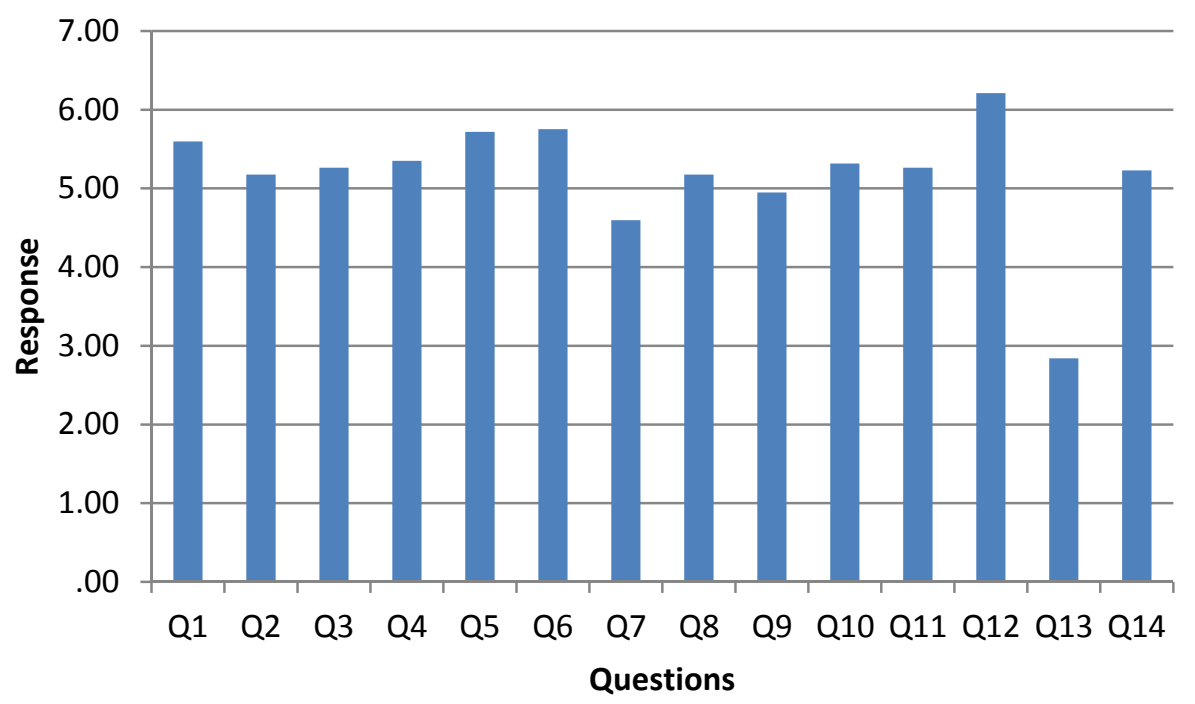

Figure 1. Mean Response for Survey Items

Different from other purely 'in-house' projects, the GIS project takes advantage of the support from ESRI and brings a rich pool of external data set via Internet. Furthermore, the external data set reflects the 'real-world' situation and is widely used for commercial purposes. Consequently, the knowledge 'gap' between college learning and real-world case can be abridged to a certain degree. From the survey results, it is proved that students welcome the use of BAO and the availability of external 'real-world' information. As high as $84.2 \%$ of participants admitted that the GIS project was the first time that they actually worked with commercially available external information in conducting a business analysis (Q6, mean value of 5.75). In addition, they liked the fact that the project helped them better understand the concepts and availability of external information that can be used to support decision making (Q5, mean value of 5.72). When examined closely, it can be found that up to 91.3\% participants welcomed the use of external information in the decision making process and a high percentage (28.1\%) of participants 'strongly agreed' that the GIS project helped them understand and apply external commercial information in decision making.

The GIS project was implemented at a group level. It is interesting to find out participants' attitude toward the team formation, size, and effectiveness in the project execution. Overall, students preferred the idea of a group project over individual assignment (Q11, 12, 13, 16). The majority of participants believed that their teams worked effectively on the GIS project (Q12, mean value of 6.21). As high as $92.9 \%$ of participants agreed that their teams were very effective. And they appreciated the fact that the teamwork requirement of the project helped them improve communication and interpersonal skills (Q11, mean value of 5.26). Because of that, most participants did not think completing the project individually would be better than working as a team (Q13, mean value of 2.84). Overall, they liked the size of their project teams (Q16, mean value of 1.93, while answer 2 means 'it was about the right size). A close investigation of the team size revealed that group size of 4 or 5 appeared perfect. A cross tabulation of group size and participants' opinions regarding team size shows that $66.7 \%$ of group of 3 thought the team size was too small while $45.5 \%$ of group of 6 stated that the team size was too big.

Lastly, the survey assessed the overall satisfaction of participants on the GIS project (Q2, 10, 14). The level of satisfaction was high with the GIS project when learning about BI and integrated business analytics in decision making (Q2, mean value of 5.18). And participants were satisfied with the project used in the course (Q14, mean value of 5.23). Up to $82.5 \%$ participants agreed that they were satisfied with the arrangement, formation, 
requirements, and outcomes of the BI GIS project. Consequently, most participants agreed (75.5\%, Q10, mean value of 5.32) that the project increased their desire to learn more about business intelligence using geographical information. In an open question asking the most important benefits participants acquired from the project, many correspondents reported that "using real data to analyze a real scenario," "learn to research and conduct spatial query using BAO," "availability of external information," "using Excel for analysis” etc.

\section{SUMMARY \& CONCLUSION}

Based on the survey results, the study found significant evidence to indicate that the implementation of BI GIS project in DSS/BI courses is appropriate and valuable. It has been a challenge for IS instructors to create or find appropriate group projects relevant to subjects in various IS courses. The concepts, process, and theories of structured decision making could be abstract, sophisticated, as well as boring to many students. A well designed project can significantly facilitate students learning, improve their learning outcomes, and increase their desire to learn more. The GIS project adopted in this study has been tested in AITP NCC contests in the past five years. Its structure, workability, level of difficulty, and BI relevance have all been proven suitable for IS majors at both graduate and undergraduate levels. Its adoption into classroom as a beneficial project for DSS/BI course was not only witnessed anecdotally [3] but examined empirically in this study. Participants can learn how to extract external information from commercially available GIS system (ESRI BAO) into Microsoft Excel to solve a 'real-world' problem. The knowledge gap between classroom learning and real-world needs is reduced, which provides a valuable learning experience for students.

\section{REFERENCES}

[1] A.S. Abrahams and T. Singh "An Active, Reflective Learning Cycle for E-Commerce Classes: Learning about E-commerce by Doing and Teaching," Journal of Information Systems Education (21:4), 2010, pp. 383-390.

[2] K. Figl "A Systematic Review of Developing Team Competencies in Information Systems Education.," Journal of Information Systems Education (21:3), 2010, pp. 323-337.

[3] R.L. Hayen "AITP NCC BI GIS Competion: A BIS Case perspective," Issues in Information Systems (XI:1), 2010, pp. 659-668.

[4] M. Mitri "Student-Developed Decision Support Systems As A Learning Aid In Industry Sector Analysis Projects," Information Technology, Learning, and Performance Journal (21:2), 2003, pp. 29-36.

[5] S.W. Palocsay and I.S. Markham "Teaching spreadsheet-based decision support systems with Visual Basic for applications," Information Technology, Learning, and Performance Journal (20:1), 2002, pp. 27-35.

[6] S.W. Palocsay, I.S. Markham and S.E. Markham "Utilizing and teaching data tools in Excel for exploratory analysis," Journal of Business Research (63:2), 2010, pp. 191-206.

[7] J.L. Schultz, J.R. Wilson and K.C. Hess "Team-based Classroom Pedagogy Reframed: The Student Perspective," American Journal of Business Education (3:7), 2010, pp. 17-24. 